\title{
A Differential Therapeutic Consideration for use of Corticosteroids According to Established COVID-19 Clinical Phenotypes in Critically III Patients
}

Gerard Moreno

Hospital Universitari de Tarragona Joan XXIII

Manuel Ruíz- Botella

Hospital Universitari de Tarragona Joan XXIII

Ignacio Martin-Loeches ( $\nabla$ drmartinloeches@gmail.com )

https://orcid.org/0000-0002-5834-4063

Josep Gómez Alvarez

Hospital Universitari de Tarragona Joan XXIII

María Jiménez Herrera

Universitat Rovira i Virgili Facultat de Medicina I Ciences de la Salut

María Amparo Bodí Saera

Joan XXIII University Hospital in Tarragona: Hospital Universitari de Tarragona Joan XXIII

Fernando Armestar

Hospital Universitari Germans Trias i Pujol

Asunción Marques - Parra

Hospital Universitario de La Ribera: Hospital La Ribera

Angel Estella

Hospital Universitario de Jerez de la Frontera

Sandra Trefler

Hospital Universitari de Tarragona Joan XXIII

Ruth Jorge García

Hospital Provincial de Nuestra Señora de Gracia: Hospital Real y Provincial Nuestra Senora de Gracia

Josefa Murcia Payá

Hospital Universitario General de Santa Lucia

Pablo Vidal Cortes

Complejo Hospitalario de Orense: Complexo Hospitalario de Ourense

Emili Díaz

Corporació Sanitària Parc Tauli: Consorcio Corporacion Sanitaria Parc Tauli

Ricard Ferrer

Hospital Vall d'Hebron: Vall d'Hebron Hospital Universitari

Antonio Albaya Moreno

University General Hospital of Guadalajara: Hospital General Universitario de Guadalajara

Lorenzo Socias Crespi

Hospital Son Llàtzer: Hospital Son Llatzer

Josep María Bonell Goytisolo

Hospital Quironsalud Palmaplanas

Susana Sancho Chinesta

Hospital Universitari i Politècnic La Fe: Hospital Universitari i Politecnic La Fe

Ana Loza

Hospital Virgen de Valme: Hospital Universitario de Valme

Lorena Forcelledo Espina

Central University Hospital of Asturias: Hospital Universitario Central de Asturias

Juan Carlos Pozo Laderas

Reina Sofía Hospital: Hospital Reina Sofia

María deAlba-Aparicio

Hospital Universitario Reina Sofía: Hospital Universitario Reina Sofia

Laura Sánchez Montori

Lozano Blesa University Clinical Hospital: Hospital Clinico Universitario Lozano Blesa

Inmaculada Vallverdu Perapoch

Hospital Universitari Sant Joan de Reus

Virginia Hidalgo 
Complejo Hospital de Segovia: Complejo Asistencial de Segovia

Virginia Fraile Gutiérrez

Rio Hortega University Hospital: Hospital Universitario Rio Hortega

Ana María Casamitjana Ortega

Hospital Universitario Materno Infantil de Canarias

Fátima Martín Serrano

Hospital Moncloa: HLA Universitario Moncloa

Mercedes Nieto

Complejo Clinico Universitario San Carlos: Hospital Clinico Universitario San Carlos

Marisa Blasco Cortes

Hospital Clínico Universitario: Hospital Clinico Universitario

Judith Marín-Corral

Hospital del Mar

Jordi Solé-Violan

Complejo Hospitalario Doctor Negrin: Hospital Universitario de Gran Canaria Dr Negrin

Alejandro Rodriguez

Hospital Universitario de Tarragona Joan XXIII/IISPV/URV https://orcid.org/0000-0001-8828-5984

\section{Research}

Keywords: Sepsis, COVID-19, Corticosteroids, Phenotypes, ICU Mortality

Posted Date: May 24th, 2021

DOI: https://doi.org/10.21203/rs.3.rs-525667/v1

License: @ (i) This work is licensed under a Creative Commons Attribution 4.0 International License. Read Full License

Version of Record: A version of this preprint was published at Medicina Intensiva on October 1st, 2021. See the published version at https://doi.org/10.1016/j.medin.2021.10.002. 


\section{Abstract}

Background: The steroids are currently used as standard treatment for severe COVID-19. However, the evidence is weak. Our aim is to determine if the use of corticosteroids was associated with Intensive Care Unit (ICU) mortality among whole population and pre-specified clinical phenotypes.

Methods: A secondary analysis derived from multicenter, observational study of adult critically ill patients with confirmed COVID-19 disease admitted to 63 ICUs in Spain. Three phenotypes were derived by non-supervised clustering analysis from whole population and classified as (A: severe, B: critical and C: lifethreatening). The primary outcome was ICU mortality. We performed a Multivariate analysis after propensity score full matching (PS), Cox proportional hazards (CPH), Cox covariate time interaction (TIR), Weighted Cox Regression (WCR) and Fine-Gray analysis(sHR) to assess the impact of corticosteroids on ICU mortality according to the whole population and distinctive patient clinical phenotypes.

Results: A total of 2,017 patients were analyzed, 1171(58\%) with corticosteroids. After PS, corticosteroids were shown not to be associated with ICU mortality (OR:1.0,95\% Cl:0.98-1.15). Corticosteroids were administered in 298/537(55.5\%) patients of "A" phenotype and their use was not associated with ICU mortality $(\mathrm{HR}=0.85[0.55-1.33])$. A total of 338/623(54.2\%) patients in "B" phenotype received corticosteroids. The $\mathrm{CPH}$ (HR =0.65 [0.46-0.91]) and TIR regression (1-25 day tHR=0.56[0.39-0.82] and $>25$ days tHR=1.53[1.03-7.12]) showed a biphasic effect of corticosteroids due to proportional assumption violation. No effect of corticosteroids on ICU mortality was observed when WCR was performed (wHR=0.72[0.49-1.05]). Finally, 535/857(62.4\%) patients in "C" phenotype received corticosteroids. The $\mathrm{CPH}(\mathrm{HR}=0.73[0.63-0.98])$ and TIR regression (1- 25 day tHR=0.69[0.53-0.89] and $>25$ days tHR=1.30[ 1.14-3.25]) showed a biphasic effect of corticosteroids and proportional assumption violation. However, wHR (0.75[0.58-0.98]) and sHR (0.79[0.63-0.98]) suggest a protective effect of corticosteroids on ICU mortality.

Conclusion: Our finding warns against the widespread use of corticosteroids in all critically ill patients with COVID-19 at moderate-high dose. Only patients with the highest severity could benefit from steroid treatment although this effect on clinical outcome was minimized during ICU stay.

\section{Introduction}

Patients with COVID-19 are known to develop a major inflammatory response that can lead to acute respiratory distress syndrome (ARDS). ARDS is a lifethreatening condition observed in many clinical situations, but particularly in sepsis, with mortality rates of about $40-60 \% 1,2$. As inflammation is thought to contribute to the pathogenesis of ARDS ${ }^{1-3}$ it warrants further investigation as to the pharmacokinetic effects of immunomodulatory agents. Further study of the interaction of these drugs with virus/host dynamics is necessary to provide insight into optimal timing of administration, dosing, and association with other interventions.

Corticosteroids are potent anti-inflammatory agents with immunomodulatory properties, which exert inhibitory effects in several stages of the inflammatory cascade, and consequently have been proposed for the treatment of ARDS ${ }^{4-6}$. In patients with HIV and ARDS due to Pneumocystis jirovecii pneumonia, prednisone represents the standard of care as it has been shown to reduce the risk of death ${ }^{7}$. However, in recent epidemics due to coronavirus infections such as that Middle East respiratory syndrome-related coronavirus (MERS-CoV) and Severe Acute Respiratory Syndrome associated coronavirus (SARS-CoV), the use of corticosteroids was associated with delayed virus clearance ${ }^{8,9}$. Moreover, in severe pneumonia caused by influenza viruses, the use of corticosteroids is not recommended because its use is associated to a higher mortality and more complications ${ }^{10,11}$.

Last year, several randomized control trials ${ }^{12-14}$ found a benefit to the use of corticosteroids in patients with COVID-19, and several clinical guidelines ${ }^{15,16}$ recommended its use to all patients with severe COVID-19 during the second wave. However, there is limited data in relation to ICU admission beyond 28 days that assesses the side effects of medium- and long-term glucocorticoid treatment and consequently limit these findings. Furthermore, short-term steroid use has been associated with opportunistic infections, even in immunocompetent hosts ${ }^{17-20}$. For example, there are still unanswered questions as to why the ICU mortality rate remains high with significant absence of clinical evidence on which subgroup or rather "phenotype' of patients could have higher response rate to the steroid therapy in question ${ }^{21}$.

This study holds that the beneficial effect of corticosteroids is seen in only some subgroups of patients with a pro-inflammatory state. Therefore, our primary objective is to identify the association of corticosteroids treatment in a whole cohort population and according to three new classified clinical phenotypes identified from 2,017 COVID-19 critically ill patients in Spain ${ }^{22}$. Our secondary objective is to stratify the competing risk factors associated with use of corticosteroids in each phenotype and clinical outcome.

\section{Material And Methods}

\section{Study design}

This study is a pre-planned secondary analysis derived from multicenter, observational study, consisting of a large-scale data source of ICU admissions and patient-level clinical data to determine differential clinical response to corticosteroid use in whole populations and in each phenotype group.

\section{Clinical phenotypes}

The characteristics of the study have been published on behalf of COVID-19 SEMICYUC working group ${ }^{22}$. In summary, to determine presence of distinct clinical phenotypes in our population of COVID-19 patients, an unsupervised clustering analysis was applied and three different clinical phenotypes were derived 
1. Cluster A phenotype (severe COVID-19 disease) included 537 patients with age $<65$ years, a lower levels of severity according an APACHE II $<15$ and SOFA $<5$, with moderate status of inflammation ( $\mathrm{LDH}<500 \mathrm{U} / \mathrm{L}$, D Dimer $<1000 \mathrm{ng} / \mathrm{mL}$ and ferritin $<1500 \mathrm{ng} / \mathrm{mL}$ ), low invasive mechanical ventilation requirements (only $0.6 \%$ ) and few development of organic dysfunction. The crude ICU mortality was $20.3 \%$.

2. Cluster B phenotype (critical COVID-19 disease) included 623 (30.8\%) with similar characteristics to group A in terms of severity and level of inflammation, but a high frequency of use of mechanical ventilation (> 70\%) and increased shock development. The crude ICU mortality was of $25 \%$

3. Cluster $\mathrm{C}$ phenotype (life-threatening COVID-19 disease) included 857 patients (42.5\%) with a high level of severity of illness (APACHE II > 15 and SOFA > 5), more likely to have elevated measures of inflammation ( $\mathrm{D}$ dimer $>2000 \mathrm{ng} / \mathrm{mL}$, LDH $>500 \mathrm{U} / \mathrm{L}$, and ferritin $>1800 \mathrm{ng} / \mathrm{mL}$ ), high frequency of invasive mechanical ventilation (> $80 \%$ ), shock, AKI and myocardial dysfunction, with a crude ICU mortality of $45.4 \%$.

\section{Corticosteroids treatment}

Corticosteroid treatment was defined as administration of prednisolone or dexamethasone; within 24-48 hours prior or first 24 hours of ICU admission. Patients receiving corticosteroids outside the established timeframe (i.e., 24-48 hours) or when hydrocortisone was administered as rescue therapy due to shock or to treat COPD/asthma exacerbation were excluded from the analysis. Methylprednisolone (40mg/day) or dexamethasone (6mg/day) were administered at the discretion of the attending physician for 7 to 10 days. Other definitions used in the study are shown in supplemental online content.

Inflammatory status was assessed through various inflammation biomarkers such as CRP, PCT, Leukocytes, Ferritin and D dimer.

Acute Kidney injury (AKI) was defined according to the Consensus Conference of the Acute Dialysis Quality Initiative $\mathrm{e}^{23}$.

Cardiac dysfunction was defined by the assistant physician with the use of two-dimensional echocardiography and was reported in the CRF as present or absent. No specific echocardiography data had been requested at the time of analysis.

\section{Cluster Homogeneity}

The homogeneity between the components in each cluster ${ }^{24}$ allows us to study the impact of a treatment (corticosteroids) within each cluster and relate that impact to the particular characteristics of the cluster. Automatic classification techniques such as "unsupervised clustering" replace the need of impulses to draw groupings arbitrarily for generating homogeneous clusters. A cluster is intrinsically homogeneous in the basis of the features used to generate the cluster. The objective of clustering analysis is to assign observations to groups (clusters), in a manner that observations in each group are similar enough between them to stand apart from other groups ${ }^{24}$. The homogeneity in each cluster allows us to study the impact of a target treatment within clusters and relate that impact among each clusters' distinctive features. This analysis was possible considering the target treatment under study was not used for cluster derivation and that treatment administered was a variable not associated with the outcome according to information value (e-Table 2 in supplementary online content). Therefore, any further impact can be seen as unbiased and independent from former analyses.

Objective: Primary: To determine whether the use of corticosteroids was associated with crude ICU mortality across the whole population and among prespecified clinical phenotypes.

\section{Secondary}

To determine which are the competing risk factors associated with corticosteroid use among pre-specified clinical phenotypes and resulting clinical outcome.

\section{Statistical analysis}

Discrete variables were expressed as counts (percentage) and continuous variables as means with standard deviation (SD) or medians and interquartile range 25-75\% (IQR). For patient demographics and clinical characteristics, differences between groups were assessed using the chi-squared test and Fisher's exact test for categorical variables, and the Student $t$ test or the Mann-Whitney $U$ test for continuous variables.

To determine if a significant inter-hospital variation in corticosteroids treatment was present, multilevel conditional logistic modelling with patients nested in hospital was employed and that further characterized hospital-level variation of ICU mortality. We built a model that recognized corticosteroids (treatment) and the specific hospital as a random variable, to assess the variation of the log-odds from one hospital to another and calculate the intraclass correlation coefficient (ICC) for one-way random-effects model.

The ICC quantifies the degree of homogeneity of the outcome within clusters and represents the proportion of the between-hospital variation in the total variation. When the ICC is not different from zero or negligible, indicates perfect independence of residuals and traditional one level regression analysis can be done (more information in electronic supplemental material)

In the first step we assess the impact of corticosteroid treatment among the general population and we performed a full-matching propensity score (PS) analysis ${ }^{26}$ in order to minimize the effect of a corticosteroid treatment selection bias and to control for potential confounding factors (additional information about the PS full-matching analysis can be found in the electronic supplementary material). This allowed us to study two comparable (almost identical) cohorts: (1) the corticosteroid-treated group and (2) the control group, comprising patients who did not receive corticosteroid treatment. PS matching analysis was used to compare outcomes between patients who have a similar distribution of all the covariates measured. An attractive feature of this approach is that it uses the entire sample. Using the PS methodology, meant all patients were assigned a weight between 0 and 1; this propensity-matched cohort was generated by choosing the best weight balance. This method optimizes the post-weighting balance of covariates between groups and, in this way, approximates the conditions of random site-of-treatment assignment. To assess our PS adjustment, we checked for adequate overlap in propensity scores 
between groups with a cross validation model. To do so, we divided the patients in the database into two subsets: (a) a "training set" with 1613 patients (80\%), and (b) a "validation set" with 404 patients (20\%). Subsequently, a logistic regression analysis for ICU mortality was carried out with the matched population to assess factors independently associated with mortality in the whole population. The results are presented as Odds ratios (OR) and $95 \% \mathrm{Cl}$ and forest plots.

In the second phase of the model, we assessed the impact of corticosteroid treatment in each predetermined phenotype. We defined cohort entry hierarchically on the basis of exposure, such as the first prescription for the drug under study. Thus, first, subjects who receive the treatment under study were considered "exposed" and entered the cohort at the time they started exposure. Following with all other subjects that are then considered unexposed, and their cohort entry is defined arbitrarily (ICU admission) by a comparison treatment. When considering patients who received corticosteroids upon admission or 48 hours prior to admission to ICU, we ensure that all patients have received the drug under study at the start of zero follow-up time (defined as ICU admission) and the immortal time bias is reduced. In addition, because Cox hazard survival analysis cannot be satisfactory for describing ICU patient mortality over time ${ }^{27}$, we performed a competing risks analysis ${ }^{28}$ to solve immortal tile bias and confirm our results (more information in electronic supplemental material)

A Kaplan-Meier survival plot was generated to track ICU mortality over time for corticosteroid-treated and untreated patients in each clinical phenotype. The information provided by each variable regarding ICU mortality was defined using the Information Value (IV). A IV greater than 0.03 was considered clinically important and this variable was included in the multivariate logistic regression analysis. In addition, Cox proportional hazards regression models were fitted to assess the impact of corticosteroids on ICU mortality in each clinical phenotype. The results are presented as hazard ratios (HR) and $95 \% \mathrm{Cl}$ and adjusted survival plots. The proportional hazards assumption was confirmed by the Schoenfeld residuals test and inspection of log (-log [survival]) curve analysis. If Schoenfeld' test showed evidence of proportional hazard violation ${ }^{27}$, we carried out two robust variations of Cox regression analysis for to solve this violation: first, a time-dependent Cox regression ${ }^{29}$ using a step function to divide the study time frame in two intervals (according to HR variation) where the proportional hazards assumption held. Secondly, a weighted Cox regression was performed which yields unbiased estimates of average hazard ratios (HR) in case of nonproportional hazards. In this way we model the effect of corticosteroids on mortality in two ranges: the short and long-term ${ }^{30}$

Finally, to investigate the association between baseline (ICU admission) variables and corticosteroid use; a multivariate analysis (binary logistic regression) was performed. The multivariate model comprised factors of clinical interest and all significant covariates in the univariate analysis. The results are presented as odds ratios (OR) and 95\% confidence intervals $(\mathrm{Cl})$. Data analysis was performed using R software (cran.r-project.org).

\section{Results}

\section{Corticosteroids treatment response in whole population: a propensity matching analysis}

A total of 2,017 critically ill patients were included in the pre-planned secondary analysis. The median (IRQ) age was 64 (55-71) years, and 1,419 (70.3\%) were men. The severity of illness was moderate according to the APACHE II (13; IQR 10-17) and SOFA (5; IQR 3-7) scores. Complete characteristics of whole and phenotype (A, B and C) population are shown in e-Table 3 in supplemental online content. An inter-hospital variation in the corticosteroids treatment was not observed, with a ICC of 0.04 . This ICC determined that the hospital-level variation was very poor (4\%).

Among 1171 patients with corticosteroid therapy, 825 (70.5\%) received methylprednisolone and $346(29.5 \%)$ dexamethasone and 50 (4.2\%) patients received hydrocortisone in combination treatment with the other steroids. No patient received hydrocortisone as the only treatment.

Patients received a median (interquartile range [IQR]) daily dose equivalent to 40 (30-60) mg of methylprednisolone and 6 (5-10) mg of dexamethasone, and the median duration of corticosteroid treatment was $7(5-10)$ days. Clinical characteristics of whole population and their distribution in the two groups are shown in Table 1. 
Table 1

Characteristics of whole population and different phenotypes according corticosteroid treatment

\begin{tabular}{|c|c|c|c|c|c|c|c|c|c|}
\hline & $\begin{array}{l}\text { Whole Populatio } \\
(n=2017)\end{array}$ & & $\begin{array}{l}\text { A Phenotype } \\
(n=537)\end{array}$ & & & $\begin{array}{l}\text { B Phenotype } \\
(n=623)\end{array}$ & & & $\begin{array}{l}\text { C Phenoty; } \\
(n=857)\end{array}$ \\
\hline \multirow[t]{2}{*}{ Variable $^{a}$} & $\begin{array}{l}\text { Corticosteroid= } \\
\text { NO } \\
n=846\end{array}$ & $\begin{array}{l}\text { Corticosteroid= } \\
\text { YES } \\
n=1171\end{array}$ & $\begin{array}{l}\text { Corticosteroid } \\
=\text { NO } \\
n=239\end{array}$ & $\begin{array}{l}\text { Corticosteroid } \\
=\text { YES } \\
n=298\end{array}$ & $\begin{array}{l}\mathrm{p}- \\
\text { value }\end{array}$ & $\begin{array}{l}\text { Corticosteroid } \\
=\text { NO } \\
n=285\end{array}$ & $\begin{array}{l}\text { Corticosteroid } \\
=\text { YES } \\
n=338\end{array}$ & $\begin{array}{l}\mathrm{p}- \\
\text { value }\end{array}$ & $\begin{array}{l}\text { Corticoster } \\
=\text { NO } \\
\mathrm{n}=\mathbf{3 2 2}\end{array}$ \\
\hline & \multicolumn{9}{|c|}{ General characteristics and severity of illness } \\
\hline $\begin{array}{l}\text { Age, median } \\
\text { (IQR), year }\end{array}$ & $65(55-72)$ & $64(56-88)$ & $63(53-69)$ & $63(54-71)$ & 0.61 & $64(50-73)$ & $63(55-71)$ & 0.71 & $66(58-73)$ \\
\hline Male, $n(\%)$ & $582(68.8)$ & $837(71.5)$ & $163(68.2)$ & 214(71.8) & 0.41 & 189(66.3) & $227(67.2)$ & 0.89 & $230(71.4)$ \\
\hline $\begin{array}{l}\text { APACHE II }{ }^{b} \\
\text { median (IQR) }\end{array}$ & $14(11-18)$ & $14(11-18)$ & $12(9-16)$ & $11.5(9-15)$ & 0.39 & $13(10-17)$ & $12(10-16)$ & 0.36 & $17(14-22)$ \\
\hline $\begin{array}{l}\text { SOFA }^{c}, \\
\text { median(IQR) }\end{array}$ & $5.0(3-7)$ & $5.7(4-8)$ & $4(3-5)$ & $4(3-5)$ & 0.61 & $5(3-7)$ & $5(3-6)$ & 0.88 & $7(5-9)$ \\
\hline \multirow{2}{*}{$\begin{array}{l}\text { GAP } \\
\text { diagnosis }{ }^{d} \\
\text { median(IQR), } \\
\text { days }\end{array}$} & $6(4-9)$ & $7(4-9)$ & $7(5-9)$ & $6.6(4-8)$ & 0.35 & $6(4-8)$ & $6(3-8)$ & 0.89 & $6(4-8)$ \\
\hline & \multicolumn{9}{|c|}{ Laboratory findings } \\
\hline $\begin{array}{l}\text { D-lactate } \\
\text { dehydrogenase, } \\
\text { median (IQR) } \\
\text { U/L }\end{array}$ & $509(405-640)$ & $\begin{array}{l}570(434- \\
765)^{\star \star \star}\end{array}$ & $\begin{array}{l}478(381- \\
547)\end{array}$ & $\begin{array}{l}463(359- \\
576)\end{array}$ & 0.49 & $\begin{array}{l}451(358- \\
543)\end{array}$ & $\begin{array}{l}492(400- \\
587)\end{array}$ & 0.001 & $\begin{array}{l}605(504- \\
800)\end{array}$ \\
\hline $\begin{array}{l}\text { White blood } \\
\text { cell, median } \\
(\mathrm{IQR}), \times 10^{9}\end{array}$ & $8.3(6.0-11.6)$ & $\begin{array}{l}9.2(6.4- \\
12.8)^{\star \star \star}\end{array}$ & $7.2(5.6-10.2)$ & 8.3(6.0-10.2) & 0.04 & $8.2(5.8-10.8)$ & $9.2(6.2-12.4)$ & 0.005 & $9.6(6.7-12$ \\
\hline $\begin{array}{l}\text { Serum } \\
\text { creatinine, } \\
\text { median (IQR), } \\
\text { mg/dL }\end{array}$ & $\begin{array}{l}0.88(0.70- \\
1.16)\end{array}$ & $\begin{array}{l}0.85(0.70- \\
1.12)\end{array}$ & $\begin{array}{l}0.80(0.66- \\
1.03)\end{array}$ & $\begin{array}{l}0.80(0.66- \\
1.01)\end{array}$ & 0.98 & $\begin{array}{l}0.82(0.65- \\
1.02)\end{array}$ & $\begin{array}{l}0.79(0.66- \\
0.97)\end{array}$ & 0.36 & $\begin{array}{l}1.0(0.78- \\
1.36)\end{array}$ \\
\hline $\begin{array}{l}\text { C-Reactive } \\
\text { Protein, median } \\
(\text { IQR), mg/dL }\end{array}$ & $15.7(9.8-24)$ & $15.3(8.9-25.0)$ & $15(9-21)$ & $14(7-22)$ & 0.36 & $\begin{array}{l}14.5(8.7- \\
21.4)\end{array}$ & $\begin{array}{l}14.4(8.0- \\
23.0)\end{array}$ & 0.82 & $18(11-27)$ \\
\hline $\begin{array}{l}\text { Procalcitonin, } \\
\text { median (IQR), } \\
\text { ng/mL }\end{array}$ & $\begin{array}{l}0.33-(0.15- \\
0.85)\end{array}$ & $\begin{array}{l}0.31(0.14- \\
0.87)\end{array}$ & $\begin{array}{l}0.29(0.14- \\
0.60)\end{array}$ & $\begin{array}{l}0.27(0.10- \\
0.68)\end{array}$ & 0.36 & $\begin{array}{l}0.21(0.12- \\
0.62)\end{array}$ & $\begin{array}{l}0.23(0.10- \\
0.50)\end{array}$ & 0.67 & $\begin{array}{l}0.61(0.24- \\
1.39)\end{array}$ \\
\hline $\begin{array}{l}\text { Serum lactate, } \\
\text { median (IQR), } \\
\mathrm{mmol} / \mathrm{L}\end{array}$ & $1.5(1.1-2.0)$ & $1.6(1.2-2.2)^{\star}$ & $1.5(1.2-1.9)$ & $1.5(1.1-2.0)$ & 0.94 & $1.3(1.0-1.8)$ & $1.5(1.1-2.0)$ & 0.002 & $1.6(1.2-2.1$ \\
\hline $\begin{array}{l}\text { D dimer, } \\
\text { median (IQR), } \\
\text { ng/mL }\end{array}$ & $\begin{array}{l}1590(720- \\
3880)\end{array}$ & $\begin{array}{l}\text { 1700(723- } \\
5990)\end{array}$ & $\begin{array}{l}\text { 1160(592- } \\
2025)\end{array}$ & $\begin{array}{l}\text { 1058(571- } \\
2370)\end{array}$ & 0.87 & $\begin{array}{l}1340(670- \\
2830)\end{array}$ & $\begin{array}{l}\text { 1305(615- } \\
3980)\end{array}$ & 0.55 & $\begin{array}{l}2200(1000 \\
4846)\end{array}$ \\
\hline $\begin{array}{l}\text { Ferritin, median } \\
(\mathrm{IQR}), \mathrm{ng} / \mathrm{mL}\end{array}$ & $\begin{array}{l}1577(1300- \\
2150)\end{array}$ & $\begin{array}{l}1668(1300- \\
2300)^{*}\end{array}$ & $\begin{array}{l}\text { 1509(1264- } \\
1825)\end{array}$ & $\begin{array}{l}1596(1300- \\
2038)\end{array}$ & 0.03 & $\begin{array}{l}\text { 1528(1267- } \\
1829)\end{array}$ & $\begin{array}{l}1580(1276- \\
2016)\end{array}$ & 0.27 & $\begin{array}{l}1780(1445 \\
2290)\end{array}$ \\
\hline
\end{tabular}

Coexisting condition and comorbidities

${ }^{*} \mathrm{p}<0.05 ; * \star p<0.01 ; * \star * p<0.001$

Abbreviations: IQR, interquartile range; APACHE II, Acute Physiology and Chronic Health Evaluation II; SOFA, Sequential Organ Failure Assessment; BMI, body obstructive pulmonary disease; HIV, human immunodeficiency viruses; PaO2/FiO2, Partial pressure arterial oxygen/fraction of inspired oxygen

a Corresponds to minimum or maximum value, as appropriate, within 12 hours of ICU admission. The variables in this Table were no transformed for your co

b APACHE II score to the severity of illness, the score is obtained by adding the following components 1) 12 clinical and laboratory variables each with a scor The APS is determined from the worst physiologic values during the initial $24 \mathrm{~h}$ after ICU admission, 2) age with a range 0 to 6 points and 3 ) Chronic health $\mathrm{p}$ history of severe organ system insufficiency or is immunocompromised assign 5 points if the patients is no operative or emergency postoperative and 2 poin patients with a total score range of 0 to 71 .

c SOFA score corresponds to the severity of organ dysfunction, reflecting six organ systems each with a score range of 0 to 4 points (cardiovascular, hepatic, neurological, renal), with a total score range of 0 to 24 ,

d GAP diagnosis include time between onset symptoms and diagnosis of COVID-19 


\begin{tabular}{|c|c|c|c|c|c|c|c|c|c|}
\hline & \multicolumn{2}{|c|}{$\begin{array}{l}\text { Whole Population } \\
(n=2017)\end{array}$} & \multicolumn{3}{|l|}{$\begin{array}{l}\text { A Phenotype } \\
(n=537)\end{array}$} & \multicolumn{3}{|c|}{$\begin{array}{l}\text { B Phenotype } \\
(n=623)\end{array}$} & \multirow{2}{*}{$\begin{array}{l}\text { C Phenotyf } \\
(n=857) \\
233(72.4)\end{array}$} \\
\hline $\begin{array}{l}\text { Arterial } \\
\text { hypertension, } \\
\mathrm{n}(\%)\end{array}$ & 283(33.4) & $526(44.9)$ & $90(37.7)$ & $121(40.6)$ & 9.54 & $83(29.1)$ & $90(26.6)$ & 0.54 & \\
\hline $\begin{array}{l}\text { Obesity (BMI > } \\
30), n(\%)\end{array}$ & 278(32.8) & $375(32.0)$ & $80(33.5)$ & $79(26.5)$ & 0.09 & $88(30.9)$ & 112(33.1) & 0.60 & $110(34.2)$ \\
\hline Diabetes, n(\%) & $171(20.2)$ & 247(21.0) & $44(18.4)$ & $68(22.8)$ & 0.25 & $56(19.6)$ & $52(15.4)$ & 0.19 & $71(22.0)$ \\
\hline $\begin{array}{l}\text { Coronary } \\
\text { arterial disease, } \\
\mathrm{n}(\%)\end{array}$ & $52(6.1)$ & $72(6.1)$ & $10(4.2)$ & $25(8.4)$ & 0.07 & $22(7.7)$ & $19(5.6)$ & 0.37 & $20(6.2)$ \\
\hline COPD, n(\%) & $66(7.8)$ & $82(7.0)$ & $16(6.7)$ & $21(7.0)$ & 1.00 & $19(6.7)$ & 19(5.6) & 0.70 & $31(9.6)$ \\
\hline $\begin{array}{l}\text { Chronic renal } \\
\text { disease, } \mathrm{n}(\%)\end{array}$ & $35(4.1)$ & $50(4.2)$ & $12(5.0)$ & $19(6.4)$ & 0.62 & $4(1.4)$ & $6(1.8)$ & 0.96 & $19(5.9)$ \\
\hline $\begin{array}{l}\text { Hematologic } \\
\text { disease, } \mathrm{n}(\%)\end{array}$ & $36(4.2)$ & $36(3.0)$ & $12(5.0)$ & $8(2.7)$ & 0.23 & $12(4.2)$ & $10(3.0)$ & 0.53 & 12(3.7) \\
\hline Asthma, n(\%) & $43(5.0)$ & $77(6.6)$ & $13(5.4)$ & $28(9.4)$ & 0.12 & $21(7.4)$ & $24(7.1)$ & 1.00 & $9(2.8)$ \\
\hline HIV, n(\%) & $3(0.3)$ & $2(0.1)$ & $1(0.4)$ & $1(0.3)$ & 1.00 & $1(0.4)$ & $0(0.0)$ & 0.93 & $1(0.3)$ \\
\hline $\begin{array}{l}\text { Pregnancy, } \\
\mathrm{n}(\%)\end{array}$ & $3(0.3)$ & $1(0.08)$ & $0(0.0)$ & $1(0.3)$ & 1.00 & $3(1.1)$ & $0(0.0)$ & 0.19 & $0(0.0)$ \\
\hline $\begin{array}{l}\text { Autoimmune } \\
\text { disease, } \mathrm{n}(\%)\end{array}$ & $29(3.4)$ & $46(3.9)$ & $5(2.1)$ & $15(5.0)$ & 0.11 & $11(3.9)$ & $7(2.1)$ & 0.27 & $13(4.0)$ \\
\hline $\begin{array}{l}\text { Chronic heart } \\
\text { disease, } \mathrm{n}(\%)\end{array}$ & $36(4.2)^{\star \star}$ & $21(1.8)$ & $14(5.9)$ & $7(2.3)$ & 0.06 & $8(2.8)$ & $2(0.6)$ & 0.06 & $14(4.3)$ \\
\hline $\begin{array}{l}\text { Neuromuscular } \\
\text { disease, } \mathrm{n}(\%)\end{array}$ & $10(1.2)$ & $6(0.51)$ & $2(0.8)$ & $1(0.3)$ & 0.84 & $4(1.4)$ & $1(0.3)$ & 0.27 & $4(1.2)$ \\
\hline \multicolumn{10}{|c|}{ Oxygenation and ventilator support } \\
\hline $\begin{array}{l}\text { Oxygen mask, } \\
\mathrm{n}(\%)\end{array}$ & $171(20.2)^{\star \star \star}$ & 154(13.1) & $61(25.5)$ & $63(21.1)$ & 0.27 & 68(23.9) & $37(10.9)$ & 0.001 & $42(13)$ \\
\hline $\begin{array}{l}\text { High flow nasal } \\
\text { cannula, } \mathrm{n}(\%)\end{array}$ & $169(19.9)$ & $206(24.3)$ & $152(63.6)$ & 193(64.8) & 0.84 & $2(0.7)$ & $1(0.3)$ & 0.88 & $15(4.7)$ \\
\hline $\begin{array}{l}\text { Non-invasive } \\
\text { ventilation, } \\
\mathrm{n}(\%)\end{array}$ & $47(5.5)$ & $93(7.9)$ & $21(8.8)$ & $43(14.4)$ & 0.06 & $8(2.8)$ & $18(5.3)$ & 0.17 & $18(5.6)$ \\
\hline $\begin{array}{l}\text { Invasive } \\
\text { mechanical } \\
\text { ventilation, } \\
\mathrm{n}(\%)\end{array}$ & $453(53.5)$ & $719(61.4)^{\star \star \star}$ & $2(0.8)$ & $1(0.3)$ & 0.84 & $200(70.2)$ & $275(81.4)$ & 0.002 & $251(78.0)$ \\
\hline $\begin{array}{l}\mathrm{PaO} 2 / \mathrm{FiO} 2 \\
\text { median (IQR) }\end{array}$ & $130(100-170)$ & ${\underset{* \star}{130}}^{130}(93-162)$ & $116(81-136)$ & 106(83-130) & 0.13 & $\begin{array}{l}167(148- \\
220)\end{array}$ & $\begin{array}{l}\text { 162(135- } \\
209)\end{array}$ & 0.05 & $124(88-15$ \\
\hline \multicolumn{10}{|c|}{ Complications and outcome } \\
\hline Shock, n(\%) & $359(42.4)$ & $545(46.5)$ & $24(10)$ & $32(10.7)$ & 0.90 & 95(33.3) & $101(29.9)$ & 0.40 & $240(74.5)$ \\
\hline AKI, n(\%) & $252(29.8)$ & $327(27.9)$ & $54(22.6)$ & $57(19.1)$ & 0.38 & $54(18.9)$ & 64(18.9) & 1.00 & $144(44.7)$ \\
\hline $\begin{array}{l}\text { Myocardial } \\
\text { dysfunction, } \\
\mathrm{n}(\%)\end{array}$ & 89(10.5) & $80(6.8)$ & $17(7.1)$ & $13(4.4)$ & 0.23 & $28(9.8)$ & $15(4.4)$ & 0.01 & $44(13.7)$ \\
\hline
\end{tabular}

$* p<0.05 ; * \star p<0.01 ; * \star * p<0.001$

Abbreviations: IQR, interquartile range; APACHE II, Acute Physiology and Chronic Health Evaluation II; SOFA, Sequential Organ Failure Assessment; BMI, body obstructive pulmonary disease; HIV, human immunodeficiency viruses; PaO2/FiO2, Partial pressure arterial oxygen/fraction of inspired oxygen

a Corresponds to minimum or maximum value, as appropriate, within 12 hours of ICU admission. The variables in this Table were no transformed for your co

b APACHE II score to the severity of illness, the score is obtained by adding the following components 1) 12 clinical and laboratory variables each with a scor The APS is determined from the worst physiologic values during the initial $24 \mathrm{~h}$ after ICU admission, 2) age with a range 0 to 6 points and 3 ) Chronic health $\mathrm{p}$ history of severe organ system insufficiency or is immunocompromised assign 5 points if the patients is no operative or emergency postoperative and 2 poin patients with a total score range of 0 to 71 .

c SOFA score corresponds to the severity of organ dysfunction, reflecting six organ systems each with a score range of 0 to 4 points (cardiovascular, hepatic, neurological, renal), with a total score range of 0 to 24 ,

d GAP diagnosis include time between onset symptoms and diagnosis of COVID-19 


\begin{tabular}{|c|c|c|c|c|c|c|c|c|c|}
\hline & \multicolumn{2}{|c|}{$\begin{array}{l}\text { Whole Population } \\
(n=2017)\end{array}$} & \multicolumn{3}{|l|}{$\begin{array}{l}\text { A Phenotype } \\
(n=537)\end{array}$} & \multicolumn{3}{|c|}{$\begin{array}{l}\text { B Phenotype } \\
(n=623)\end{array}$} & \multirow{2}{*}{$\begin{array}{l}\text { C Phenotyf } \\
(n=857) \\
222(68.9)\end{array}$} \\
\hline $\begin{array}{l}>2 \text { quadrant } \\
\text { infiltrates in } \\
\text { chest x-ray, } \\
\mathrm{n}(\%)\end{array}$ & $542(64.0)$ & $788(67.2)$ & $141(58.9)$ & $203(68.1)$ & 0.02 & $179(62.8)$ & $234(69.2)$ & 0.09 & \\
\hline $\begin{array}{l}\text { Ventilator } \\
\text { associated } \\
\text { pneumonia }\end{array}$ & $116(13.7)$ & $210(17.9)$ & $35(14.6)$ & $38(12.8)$ & 0.61 & $34(11.9)$ & 63(18.6) & 0.02 & $47(14.6)$ \\
\hline ICU LOS & $13(5.4-23)$ & $15(9.0-27)^{\star \star \star}$ & $12(5-26)$ & $11(6-21)$ & 0.65 & $13(5-20)$ & $14(8-25)$ & 0.001 & $15(7.0-24$. \\
\hline $\begin{array}{l}\text { ICU crude } \\
\text { mortality, } \mathrm{n}(\%)\end{array}$ & $261(30.8)$ & $396(33.8)$ & 47(19.7) & $62(20.8)$ & 0.82 & $72(25.3)$ & $87(25.7)$ & 0.96 & $142(44.1)$ \\
\hline
\end{tabular}

$* p<0.05 ; * \star p<0.01 ; * \star \star p<0.001$

Abbreviations: IQR, interquartile range; APACHE II, Acute Physiology and Chronic Health Evaluation II; SOFA, Sequential Organ Failure Assessment; BMI, body obstructive pulmonary disease; HIV, human immunodeficiency viruses; PaO2/FiO2, Partial pressure arterial oxygen/ fraction of inspired oxygen

a Corresponds to minimum or maximum value, as appropriate, within 12 hours of ICU admission. The variables in this Table were no transformed for your co

b APACHE II score to the severity of illness, the score is obtained by adding the following components 1) 12 clinical and laboratory variables each with a scor The APS is determined from the worst physiologic values during the initial $24 \mathrm{~h}$ after ICU admission, 2) age with a range 0 to 6 points and 3 ) Chronic health $\mathrm{p}$ history of severe organ system insufficiency or is immunocompromised assign 5 points if the patients is no operative or emergency postoperative and 2 poin patients with a total score range of 0 to 71 .

c SOFA score corresponds to the severity of organ dysfunction, reflecting six organ systems each with a score range of 0 to 4 points (cardiovascular, hepatic, neurological, renal), with a total score range of 0 to 24 ,

d GAP diagnosis include time between onset symptoms and diagnosis of COVID-19

Patients who received corticosteroid therapy had similar characteristics to those who did not receive them, except for the following measures: lactate dehydrogenase, WBC, ferritin and use of mechanical ventilation. The crude ICU mortality was $32.6 \%$ and similar for patients with (33.8\%) and without corticosteroids (30.8\%) (Table 1$)$.

PS matching was applied, and 846 control and 1171treated patients were matched. The summaries of balance for unmatched and matched data are shown in e-Figure 1 in the supplementary material. When multivariate analysis (GLM) for ICU mortality was performed, corticosteroids treatment was not associated with mortality $(\mathrm{OR}=1.0 ; 95 \% \mathrm{Cl} 0.98-1.15)$ (e-Table 4). The discriminatory power of the model (e-Figure 2) was high, with an area under the receiver operating characteristic curve of $0.78(95 \% \mathrm{Cl} 0.75-0.82, \mathrm{p}<0.01)$. The accuracy of the predictive model (training set) with respect to the validation set was 0.75 .

\section{Corticosteroids Treatment Response Among The A Phenotype}

Therapeutic impact among the A phenotype, was assessed among 298 (55,5\%) patients that received corticosteroids as co-adjuvant therapy for viral pneumonia (Table 1). The crude ICU mortality was $20.3 \%$. Non-survivors' $(n=109)$ were older $(70$ vs $60 ; p=0.001)$, with high severity of illness assessed by APACHE II (15 vs 11, p = 0.001) and SOFA ( 5 vs 3, p = 0.001), higher inflammatory status and more incidence of acute kidney injury (AKI: $48.6 \%$ vs $13.6 \%, p=$ $0.001)$ and myocardial dysfunction $(15.6 \%$ vs. $3.0 \%, p=0.001)$ than survivors. Conversely, corticosteroid treatment was not associated with mortality (eTable 5 in supplemental online content). Ventilator-associated pneumonia diagnosis was not significantly different between patients with (12.8\%) and without $(14.6 \%, p=0.61)$ corticosteroids treatment. Table 1

The unadjusted probability of survival over the time (Kaplan-Meier plot) is shown in e-Figure 3 in supplemental online content. No significant differences were observed $(p=0.58)$ between patients with and without corticosteroids treatment. Only 28 of the 49 controlled variables exceeded the predefined cut-off point for the information value and were included in the cox model (e-Table 6 in supplemental online content). The use of Corticosteroids had no effect on ICU mortality ( $\mathrm{HR}=0.8595 \% \mathrm{Cl} 0.55-1.33)$ (Fig. $1 \mathrm{~A}$ and e-Table 7 in supplemental online content). The Schoenfeld' test $(p=0.06)$ was not statistically significant and assume the proportional hazards (e-Figure 4 in the supplemental online content). When a multivariate Fine and Gray regression model was used (Fig. 1B), corticosteroid use remained as a factor not associated with mortality (SHR $=0.85[95 \% \mathrm{Cl} 0.55-1.83)$.

No significant differences were observed in laboratory findings or clinical characteristics of patients that received or not corticosteroids (Table 1 ), except for white blood cell counts(WBC), serum ferritin and the number of patients with more than 2 quadrant infiltrates in chest $x$-ray, that were noted as significantly more frequent in patients that received corticosteroid. These variables plus variables clinically relevant as APACHE II, SOFA, age, invasive mechanical ventilation(IMV), obesity and CRP were included in the multivariate analysis. Only presence more than 2 quadrant infiltrates in chest $\mathrm{x}$-ray $(\mathrm{OR}=1.5 ; 95 \% \mathrm{Cl}$ 1.05-2.16) was independently associated with use of corticosteroids. (e-Table 8 in the supplemental online content)

\section{Corticosteroids Treatment Response Among The B Phenotype}

Therapeutic impact among the B phenotype, was assessed among $338(54,2 \%)$ patients that received corticosteroids as co-adjuvant therapy for viral pneumonia (Table 1). The crude ICU mortality was $25.5 \%$. Non-survivors' $(n=159)$ patients were older $(71$ vs $61 ; p=0.001)$, with high severity of illness assessed by APACHE II (15 vs $12, p=0.001)$ and SOFA ( 6 vs $4, p=0.001)$, higher inflammatory status and more incidence of AKI $(37.7 \%$ vs $12.5 \%, p=0.001)$ 
and myocardial dysfunction $(11.9 \%$ vs. $5.2 \%, p=0.001)$ than survivors. Only COPD was more frequent in non-survivors. Ventilator-associated pneumonia diagnosis was more frequent in patients with $(18.6 \%)$ than without corticosteroids treatment $(11.9 \%, p=0.02)$. Table 1

Conversely, corticosteroid treatment was not associated with mortality (e-Table 9 in supplemental online content).

The unadjusted probability of survival over the time (Kaplan-Meier plot) is shown in e-Figure 5 in supplemental online content. No significant differences were observed $(p=0.58)$. However, a cross-link between groups with or without corticosteroids is observed and a proportional hazards $(\mathrm{PH})$ violation should be suspected.

Only 20 of the 49 controlled variables exceeded the predefined cut-off point for the information value and were included in the cox model (e-Table 6 in supplemental online content). Corticosteroid treatment was associated with protected effect ( $\mathrm{HR}=0.65 ; 95 \% \mathrm{Cl} 0.46-0.91)$ for ICU mortality (Fig. $2 \mathrm{~A}$ and eTable 10 in supplemental online content). However, we observed in the Cox plot that the covariate of primary interest (corticosteroids) has different short-term (1-35 days) and long-term effects (> 36 days) and a violation of proportional hazards $(\mathrm{PH})$ assumption was confirmed by the Schoenfeld test ( $\mathrm{p}=0.04)(\mathrm{e}-$ Figure 6) and HR obtained can sub or overestimate the corticosteroid effect.

To try to fix this limitation, a Cox time step interaction analysis was conducted. Corticosteroid treatment showed a protective effect $(\mathrm{HR}=0.56$, $95 \mathrm{Cl} 0.39-$ 0.81 ) until 25 days, however, the corticosteroid: time step interaction resulted in an increment of risk of death respective of basal risk (tHR $=2.71,95 \mathrm{Cl} 1.03-$ 7.12) after 25 days (Fig. 2B). To confirm these findings a weighted Cox Regression analysis was performed, that confirmed no association between corticosteroids treatment and ICU mortality ( $w H R=0.72,95 \% \mathrm{Cl} 0.49-1.05 ; \mathrm{p}=0.096)$. Finally, the multivariate Fine and Gray regression model used (Fig. $2 \mathrm{C}$ ), did confirm corticosteroid use was associated with mortality (SHR $=0.65[95 \% \mathrm{Cl} 0.46-0-91)$.

No significant differences were observed in laboratory findings or clinical characteristics of patients that received or not corticosteroids (Table 1), except for Dlactate dehydrogenase, WBC, serum lactate, and IMV use more frequent in patients with corticosteroid treatment. Development of ventilator-associated pneumonia was higher in patients with corticosteroids treatment $18.6 \%$ vs $11.9 \%, p=0.02$ (Table 1 )

These variables plus clinically relevant variables as APACHE II, SOFA, age, IMV, obesity and CRP were included in the multivariate analysis. D-lactate dehydrogenase $(\mathrm{LDH} ; \mathrm{OR}=1.0$ [1.01-1.2]), serum lactate $(\mathrm{OR}=1.1[1.03-1.26])$, WBC count $(\mathrm{OR}=1.04[1.01-1.08])$ were independently associated with use of corticosteroids (e-Table 11 in the supplemental online content).

\section{Corticosteroids Treatment Response Among The C Phenotyp}

Therapeutic impact among the $\mathrm{C}$ phenotype, was assessed among $535(62.4 \%)$ patients that received corticosteroids as co-adjuvant therapy for viral pneumonia (Table 1). The crude ICU mortality was $45.4 \%$. Non-survivors' $(n=389)$ patients were older ( 68 vs $63 ; p=0.001)$, with high severity of illness assessed by APACHE II (18 vs $15, p=0.001)$ and SOFA (7.4 vs $7.0, p=0.001)$ than survivors. Corticosteroid treatment was not associated with mortality as shown in (e-Table 12 in supplemental online content).

The unadjusted probability of survival over the time (Kaplan-Meier plot) is shown in e-Figure 7 in supplemental online content. No significant differences were observed $(p=0.06)$. However, similar to B phenotype a cross-link between groups with or without corticosteroids is observed.

Only 20 of the 49 controlled variables exceeded the predefined cut-off point for the information value and were included in the cox model (e-Table 6 in supplemental online content). Corticosteroid treatment was associated with a protected effect ( $\mathrm{HR}=0.73 ; 95 \% \mathrm{Cl} 0.63-0.98)$ for ICU mortality (Fig. $3 \mathrm{~A}$ and eTable 13 in supplemental online content). However, we observed in the Cox plot that the covariate of primary interest (corticosteroids) has different short-term (1-25 days) and long-term effects ( $>25$ days). The Schoenfeld test $(p=0.04)$ confirmed PH violation (e-Figure 8). When Cox time step interaction analysis was employed, corticosteroid treatment showed a clear protective effect $(\mathrm{HR}=0.69,95 \% \mathrm{Cl} 0.53-0.89)$ until 25 days, but resulted in an increment of risk of death respective of basal risk ( $\mathrm{tHR}=1.93,95 \% \mathrm{Cl} 1.14-3.25$ ) after 25 days (Fig. 3B). However, when weighted Cox Regression analysis was performed, corticosteroids treatment showed a protective effect on ICU mortality ( $w H R=0.75,95 \% \mathrm{Cl} 0.58-0.98 ; \mathrm{p}=0.03$ ). Finally, Fine and Gray regression model used (Fig. 3C) confirmed corticosteroid treatment as a protective factor for ICU mortality (SHR $=0.79[95 \% \mathrm{Cl} 0.63-0.98)$.

No significant differences were observed in laboratory findings or clinical characteristics of patients that received or not corticosteroids (Table 1), except for LDH higher in patients with corticosteroid treatment. Development of ventilator-associated pneumonia was higher in patients with corticosteroid treatment ( $20.4 \%$ vs. $14.6 \%, p=0.04)$ Table 1 . These variables plus clinically relevant variables as APACHE II, SOFA, age, IMV, obesity and CRP were included in the multivariate analysis. Only $\mathrm{LDH}(\mathrm{OR}=1.0,95 \% \mathrm{Cl} 1.01-1.02)$ was noted to be independently associated with use of corticosteroids. (e-Table 14 in supplemental online content)

\section{Discussion}

This represents the first built machine learning model used to assess the effect of corticosteroids therapy according to pre-defined clinical phenotypes among a large cohort of critically ill patients with severe COVID-19 disease. The main finding of our study is that the use of corticosteroids was not associated with improved outcomes in all critically ill patients with COVID-19 at moderate /high dose and this effect appears to be bi-phasic, with an early reduction and a late increase in risk of death. This late increase of mortality risk could be related to the development of infectious complications such as ventilator-associated pneumonia as we observed in B and C phenotypes 
The challenge in developing optimal treatment strategies is the extreme heterogeneity of presentation in COVID-19 patients who are critically ill ${ }^{21,22}$. The ability of identifying phenotypes in COVID-19 patients, using a small set of variables, is a crucial step towards clinical application and has important implications for possible differential mechanism-driven phenotype compound screening. Consequently, our study suggests that only clinical phenotypes with some degree of systemic inflammation, such as the defined phenotype $\mathrm{C}$, may have an early benefit from steroid treatment, although this benefit decreases as time spent in ICU increases. Benefits offered by corticosteroids in attenuating immune dysregulation must be balanced with their inhibitory effect on the immune response needed to control viral replication, as well as risk of opportunistic infections and associated side-effects ${ }^{15}$.

\section{Evidence Summary:}

Data regarding the efficacy of corticosteroids in the treatment of SARS-CoV-2 is difficult to interpret. By the second wave of COVID-19, literature evolved rapidly, and the most recent findings position corticosteroids as strong candidates for treatment. Data from the RECOVERY Trial ${ }^{12}$ and WHO meta-analysis ${ }^{15}$, supported the administration of $6 \mathrm{mg}$ dexamethasone internationally for all patients with SARS CoV-2 infection who required oxygen supplementation or invasive mechanical ventilation. However, the role of corticosteroids in the treatment of COVID-19 remains controversial according to recent meta-analysis results ${ }^{6,31-36}$ and whether [corticosteroids] should be used to treat SARS-associated lung injury in any stage of illness, particularly as the drug is immunosuppressive and may delay viral clearance in the patient. A recent study in France ${ }^{37}$ comparing first vs second wave reported that despite of the systematic and early administration of glucocorticoids in the second wave, the ICU mortality $(50 \%$ vs. $52 \%, p=0.96)$ and duration of ICU stay did not differ between the two waves. In contrast, Wu C et al. ${ }^{38}$ observed in 380 patients that, low-dose corticosteroid treatment was associated with reduced risk of inhospital death within 60 days in COVID-19 patients who developed ARDS. However, it should be noted that this study only included patients with ARDS, and corticosteroids were initiated 13 days after symptom and this is not the usual clinical practice for the use of corticosteroids in COVID-19.

Chen et $\mathrm{al}^{21}$ observed presence of two phenotypes (hypo and hyper-inflammatory) among COVID-19 patients. Interestingly, after applying a marginal structural modeling, the association between corticosteroid therapy and 28-day mortality was only observed in patients with the hyper-inflammatory phenotype (HR, $0.51 ; 95 \% \mathrm{Cl}, 0.34-0.78)$. The findings from this study are consistent with our results, where only the phenotypes B and $\mathrm{C}$, that are characterized with a higher inflammatory status, seem to have an early stage of illness benefit from corticosteroid treatment.

While the anti-inflammatory effects of corticosteroids have potential benefit in reducing cytokine production and edema, corticosteroids suppress a number of critical cellular immune functions that could impair viral clearance and lead to secondary infections ${ }^{39}$. In addition, corticosteroids, have been shown to decrease B cell production of immunoglobulins and induce T cell apoptosis, two immune cellular effects that would be counterproductive in COVID-19. We can hypothesize that the immunosuppressive effect of corticosteroids coupled with the state of immunosuppression secondary to COVID-19 may ultimately negatively alter host immune response resulting in increased susceptibility to infections and/or hypersensitivity states as we have seen in the most inflamed phenotypes ( $B$ and $C)$. Although the effect of corticosteroids can be extended up to 72 hours after the last dose $\mathrm{e}^{40,41}$, the duration of the effect immunosuppressive in COVID-19 patients has not been evaluated.

This is contrary to the current recommendation of dexamethasone treatment according to the RECOVERY trial ${ }^{12}$, a multicenter, randomized, open-label trial in hospitalized patients with COVID-19 that showed that the mortality from COVID-19 was lower among patients who were randomized to receive dexamethasone than among those who received the standard of care. Several limitations have been reported since its publication ${ }^{4,5,42,43}$. Possibly the most important limitation is the lack of an adjustment according to severity of illness to minimize potential bias. Another potential limitation could be related to the selection bias, especially in the subgroup of patients receiving IMV in which an average of only 6 patients were included per center. In addition, overall, $22.9 \%$ of participants in the dexamethasone arm and $25.7 \%$ in the standard of care arm died within 28 days of study randomization. It represents a $2.8 \%$ of mortality reduction which, although statistically significant by the high number of patients included, its clinical significance seems scarce. Finally, mortality has been censored at 28 days, and no data have been published from the mortality at ICU or Hospital discharge. Our study warns of the loss of the early steroids beneficial effect with the ICU LOS and the appearance of a late increase in the risk of death, possibly in relation to further development of infectious complications such as ventilator-associated pneumonia in patients receiving corticosteroids (specifically, in phenotypes B and C).

Survival benefit detailed in the RECOVERY trial ${ }^{12}$ appeared greatest among patients who required IMV. These findings are consistent with our results, as between $70-80 \%$ of patients in phenotypes $B$ and $C$ required ventilation and then could benefit from steroids. Moreover, several risk factors known to contribute to mortality in COVID-19, including severity of hypoxemia, ventilator settings and other types of organ support were not reported in RECOVERY12. As a last point, in the RECOVERY trial ${ }^{12}$ a favorable effect on survival was evident with the use of steroids treatment among patients who only required supplemental oxygen (rate ratio $0.82 ; 95 \% \mathrm{Cl}, 0.72-0.94$ ). This sub-group of patients can be said to represent a similar profile to that of the A Phenotype from our study, where more than $80 \%$ of patients received only supplemental oxygen at ICU admission and the crude ICU mortality was $20 \%$. However, we do not observe the impact of corticosteroid treatment on survival in this phenotype.

The clinical and biological heterogeneity of patients with COVID-19 is the main dead endpoint to administer the proper treatment ${ }^{22}$. No isolated clinical or biological variable is sufficient to distinguish patients from each other. The added value of this model was attributed to the new analysis methodologies (unsupervised clustering) which allowed us to identify three different clinical phenotypes of COVID-19 based on their clinical and laboratory characteristics ${ }^{22}$. Against what is suggested by the RECOVERY trial, our results strongly suggest that corticosteroid treatment represents a bi-phasic action and should not be administered to patients who do not require mechanical ventilation independently of their hypoxemia level. Differences in results could be due to our patient adjustment modelling according to severity in illness and the absence of stratification and incomplete information about some factors associated with outcome in the RECOVERY trial may have resulted in imbalance between the treated and control ${ }^{34}$. 
However, some study limitations should be noted when considering the added value of this machine learning model clinically. First, although phenotypes were found to be generalizable in our population (after validation), risk factors and characteristics that pre-defined these clinical phenotypes were derived initially from data at ICU admission of a multicenter observational study in Spain. However, at the same time these risk factors are similar to those that have been reported by other investigators ${ }^{38-47}$ which suggests its applicability to other populations. Despite this, our phenotypes should be validated into other critical patient populations to assess reproducibility and cross-application.

Second, only routinely available clinical data at ICU admission was used to identify risk factors and clinical phenotypes, and the inclusion of other data related to clinical evolution of patients in the ICU could change risk factors or phenotype assignments. However, our objective was to study early risk factors and phenotypes at ICU admission that may allow for early treatment implementation and as a result improve patient outcome.

Third, this is a sub-analysis conducted following the author's primary observational study in order to consider only segmental measured confounders. The authors are aware of the limitations presented by the exclusion of other residual measured confounders and unmeasured confounders that could not be included fully.

Finally, this study did not collect data that could assess the impact of ethnicity, socioeconomic factors o long-term complications. These factors may play a role in the prevalence of pre-existing comorbidities and mortality due to COVID-19.

\section{Conclusion}

Given the paucity of randomized controlled trials of immunomodulatory therapies in COVID-19 critically ill patients, we have provided the above guidance. Our findings warn against the widespread use of corticosteroids in all critically ill patients with COVID-19 according to the moderate-high dose. Observing the biphasic effect of steroids with a late increase in the risk of death and the development of further infectious complications in corticosteroid patients, suggests the need to determine within each phenotype what subset of patients may really benefit from treatment. Thus, avoiding the risk of late superinfections. Further randomized controlled trials of immunomodulatory therapies in critically ill patients according to different phenotypes are warranted that take into account other outcomes that were not explored in our model associated with corticosteroid therapy, such as severe acute respiratory syndrome coronavirus, RNA clearance, superinfections, delirium, and gastrointestinal bleeding, as well as long-term time-dependent follow-up data for COVID-19 patients.

\section{Declarations}

\section{Acknowledgements}

To Alexis Garduno for English manuscript edition and to the COVID-19 SEMI-

CYUC Investigators

Authors' contributions

AR, MRB, IML, MJH, JSV, JG, MB, ST, EP, ED, BS, MV, EMV, AAM, JASG, MDVO, JCB, LMI, JMC, ELR, VHV, LV, SSC, FJGM, SHG, CCSP, JCPL, and RRG had substantial contributions to conception and design of the work. AR, ST, MJH, MRB and JG had substantial contribution for data acquisition. AR, MRB, IML, JG, $M B$ had substantial contribution for data analysis and interpretation of data for the work. AR, IML, MB, JSV and ED drafting of the manuscript. RF, IML, MB, ED, BS, JCB, SSC, FJGDM critically reviewed the draft manuscript. The corresponding and last authors (AR\&IML) had full access to all the data in the study and takes responsibility for the integrity of the data and the accuracy of the data analysis. All authors approved the final version of the manuscript. The views expressed in this article are those of the authors and not necessarily those of the SEMICYUC.

Funding

This study was supported by the Spanish Intensive Care Society (SEMICYUC), Ricardo Barri Casanovas Foundation Grant (A. Rodríguez) and Pla Estratègic de Recerca i Innovació en Salut- Generalitat de Catalunya PERIS SLT017/20/000030 (M.Bodi, M Ruíz-Botella, J Gómez, A.Rodríguez) and SFI - COVID-RRC ref: 20/COV/0038 (Ignacio Martin-Loeches)

\section{Availability of supporting data}

The anonymized database collected for the study by the SEMICYUC, and the data dictionary that defines each field in the set, will be made available to reviewers if they consider it necessary prior confidentiality agreement.

Ethical approval and consent to participate

The study was approved by the reference institutional review board at Joan XXIII University Hospital (IRB\# CEIM/066/2020) and each participating site with a waiver of informed consent.

$\underline{\text { Consent for publication }}$

Not applicable.

$\underline{\text { Competing interests }}$

Page 11/19 
The authors declare that they have no competing interest

Study group

Andalucía:

UCI Hospital Universitario Virgen de Valme (Sevilla): Ana Loza; UCI Hospital

Quirón (Huelva): Diego Matallana Zapata; UCI Hospital Universitario Puerto

Real (Cádiz): Isabel Díaz Torres, Sonia Ibañez Cuadros, María Recuerda Nuñez,

Maria Luz Carmona Pérez, Jorge Gómez Ramos, Alba Villares Casas; UCI Hospi-

tal Universitario Virgen de la Macarena (Sevilla): María Luisa Cantón, José Javier González Contreras, Helena Pérez Chomón, Nerissa Alvarez Chicote, Alberto Sousa González; UCI Hospital Universitario Reina Sofía (Córdoba): María De Alba Aparicio, Juan Carlos Pozo Laderas; UCI Hospital Universitario de Jerez (Jerez de la Frontera): Angel Estella, Sara moreno Cano. UCI Hospital Infanta Elena (Huelva): Diego Matallana Zapata.

Aragón:

UCI Hospital Nuestra Señora de Gracia (Zaragoza): Ruth Jorge García; UCI Hospital Clínico Universitario Lozano Blesa (Zaragoza): Laura Sánchez Montori, Sandra Herrero García, Paula Abanses Moreno, Carlos Mayordomo García.

UCI Hospital General San Jorge(Huesca): Tomás Mallor Bonet, Paula Omedas Bonafonte, Enric Franquesa Gonzalez, Nestor Bueno Vidales, Paula Ocabo Buil, Carlos Serón Arbeloa; UCI Hospital Universitario Miguel Servet(Zaragoza): Isabel Sancho, Pablo Guerrero Ibañez, Pablo Gutierrez, UCI Hospital Obispo Polanco (Teruel): María Concepción Valdovinos, Raquel Canto.UCI Hospital Nuestra Señora de Gracia (Zaragoza): Ruth Jorge García; UCI Hospital Clínico Universitario Lozano Blesa (Zaragoza): Laura Sánchez Montori, Sandra Herrero García, Paula Abanses Moreno, Carlos Mayordomo García. UCI Hospital General San Jorge(Huesca): Tomás Mallor Bonet, Paula Omedas Bonafonte, Enric Franquesa Gonzalez, Nestor Bueno Vidales, Paula Ocabo Buil, Carlos Serón Arbeloa; UCI Hospital Universitario Miguel Servet(Zaragoza): Isabel Sancho, Pablo Guerrero Ibañez, Pablo Gutierrez, UCI Hospital Obispo Polanco (Teruel): María Concepción Valdovinos, Raquel Canto.

Asturias:

UCI Hospital Universitario San Agustín (Avilés): Ana Luz Balán Mariño, María José Gutiérrez Fernández, Marta Martín Cuadrado, Belén García Arias; UCI Hospital Universitario Central de Asturias (Oviedo): Lorena Forcelledo Espina, Lucía Viña Soria, Lorena Martín Iglesias, Lucía López Amor, Elisabet Fernández Rey, Emilio García Prieto. UCI Hospital Cabueñes (Gijón): Débora Fernández 
Ruíz, Carla Martínez González.

Baleares:

UCI hospital Universitario Son Llatzer (Palma de Mallorca): Lorenzo Socias, Marcio Borges-Sá, María Aranda Pérez, Antonia Socias. UCI Hospital Quirón Salud Palmaplanas (Palma de Mallorca): José Ma Bonell Goytisolo, Inmaculada Alcalde Mayayo, Carlos Corradini, Isabel Ceniceros, Edwin Rodríguez; UCI Hospital Universitario Son Espases (Palma de Mallorca): Jose Ignacio Ayestarán Rota, Mariana Andrea Novo Novo, Joaquim Colomina Climent, Albert Figueras Castilla, Tomàs Leal Rullan, Maria Magdalena Garcias Sastre; UCI Hospital Comarcal d'Inca(Inca): Rossana Pérez Senof; UCI Hospital Mateu Orfla (Mao): Ramón Fernández-Cid Bouza.

Canarias:

UCI Complejo Hospitalario Universitario Insular-Materno Infantil (Las Palmas de G.C): Juan Carlos Martín González, Carmen Pérez Ortiz, José Luciano Cabrera Santana, Juan José Cáceres Agra, Domingo González Romero, Ana Casamitjana Ortega; UCI Hospital General de la Palma (Tenerife): Luis Alberto Ramos Gómez, Carolina Montelongo Ojeda; UCl Hospital Universitario Dr. Negrín (Las Palmas de G.C): Jordi Solé-Violán.

Cataluña:

UCI Hospital Universitari de Tarragona Joan XXIII (Tarragona): Alejandro Rodríguez, María Bodí, Gerard Moreno, Sandra Trefer, Laura Claverias, Raquel Carbonell, Erika Esteve, Montserrat Olona, Xavier Teixidó. UCI Hospital Universitari Arnau de Vilanova (Lleida): Monserrat Vallverdú Vidal, Begoña Balsera Garrido. UCI Hospital Universitari Vall d'Hebron (Barcelona): Elisabeth Papiol Gallofré, Raquel Albertos Martell, Rosa Alcaráz Peñarrocha, Xavier Nuvials Casals, Ricard Ferrer Roca; UCI Hospital Verge de la Cinta (Tortosa): Eric Adrián Mayor Vázquez, Ferrán Roche Campo, Pablo Concha Martínez, Diego Franch Llasat;UCI Hospital del Mar (Barcelona): Joan Ramón Masclanz, Judith MarínCorral, Purifcación Pérez, Rosana Muñoz, Clara Vila; UCI Hospital Mutua de Terrasa (Terrasa): Francisco Javier González de Molina, Elisabeth Navas Moya, Josep Trenado; UCl Hospital Sant Joan (Reus): Imma Vallverdú, Eric Castañé; UCI Hospital Parc Tauli (Sabadell): Emili Díaz Santos, Gemma Goma, Edgar

Moglia.

Cantabria

UCI Hospital Universitario Marqués de Valdecillas(Santander): Borja Suberviola.

Rodríguez et al. Crit Care (2021) 25:63 Page 14 of 15

Castilla La Mancha: 
UCI Hospital Universitario de Guadalajara (Guadalajara): Antonio Albaya

Moreno, Carlos Marian Crespo. UCI Hospital Nuestra Señora del Prado (Toledo):

Carmen Carolina Sena Pérez, Francisca Arbol Linde.UCI Hospital Universitario

de Guadalajara (Guadalajara): Antonio Albaya Moreno, Carlos Marian Crespo.

UCI Hospital Nuestra Señora del Prado (Toledo): Carmen Carolina Sena Pérez,

Francisca Arbol Linde.

Castilla y León:

UCI Hospital Virgen de la Concha (Zamora): Diana Monge Donaire, Vega

Losada Martínez, Nuria Rodrigo Castroviejo, Gerardo Ferrigno, Reyes Beltrán,

Carolina Sanmartino, Concepción Tarancón Maján, Alfredo Marcos Gutiér-

rez; UCI Complejo Asistencial de Segovia(Segovia): Virginia Hidalgo Valverde, Caridad Martín López; UCI Hospital universitario de Burgos (Burgos): Oihane

Badallo, María del Valle Ortiz, Rebeca Vara Arlanzón, David Iglesias Posadilla;

UCI Hospital Clínica de Salamanca (Salamanca): María Teresa Recio, Juan Carlos

Ballesteros; UCl Complejo Asistencial Universitario de Palencia (Palencia).

Ceuta

UCI Hospital Universitario de Ceuta: Enrique Laza Laza.

Extremadura

UCI Hospital San Pedro de Alcántara (Cáceres): Elena Gallego Curto, Mª Carmen Sánchez García; UCl Hospital de Mérida(Mérida): Miguel Díaz-Tavora, Rosa

Mancha.

Galicia:

UCI Hospital Montecelo (Pontevedra): Ana Ortega Montes, Isabel Gallego

Barbachano, Eva Sanmartín Mantiñán. UCI CHUAC A Coruña (A Coruña): María

Lourdes Cordero, Raquel María Rodríguez García, Jorge Gámez Zapata, María

Gestal Vázquez. UCI Centro Hospital Universitario de Ferrol (Ferrol): María

José Castro Orjales, María Isabel Álvarez Diéguez. UCI Hospitalario Clínico

Universitario de Santiago (Santiago de Compostela): Carmen Rivero Velasco,

Beatriz Lence Massa; REA CHUAC A Coruña (A Coruña): María Gestal Vázquez.

UCI Hospital Lucus Augusti (Lugo): Ignacio Martínez Varela.

Huelva:

UCI Hospital Infanta Elena (Huelva): Diego Matallana Zapata.

Madrid:

UCI IFEMA (Madrid): Alberto Hernández Tejedor; UCI Hospital Príncipe de

Asturias (Madrid): Esther Mª López Ramos, Laura Alcázar Sánchez Elvira, Rocío

Molina Montero, Ma Consuelo Pintado Delgado, María Trascasa Muñoz de

Page 14/19 
la Peña, Yaiza Betania Ortiz de Zárate Ansotegui, Alejandra Acha Aranda, Juan Higuera Lucas; UCI Hospital de la Princesa (Madrid): Juan Antonio Sanchez Giralt, Marta Chicot Llano, Nuria Arevalillo Fernández, Marta Sánchez Galindo, Ricardo Andino Ruiz, Alfonso Canabal Berlanga; UCI Hospital Clinico San Carlos (Madrid): Miguel Sánchez, Mercedes Nieto; UCI Hospital HLA la Moncloa(Madrid): Eduardo Arias Sarmiento, Adoración Bueno Blázquez, Rosa María de la Casa, Fátima Martín, Samuel González López.

Murcia

UCI Hospital Morales Meseguer (Murcia): Elena Martínez Quintana, Bernardo

Gil Rueda, Áurea Higon Cañigral, Laura López Gómez, Pablo Safwat Bayoumi Delis, Augusto Montenegro Muore, Ángel Andrés Agamez Luengas; UCI Hospital Clínico Universitario Virgen de la Arrixaca (Murcia): Enriqueta Andreu Soler, Ana Beatriz Pérez Pérez, José Higinio de Gea García, Rubén Jara Rubio, Silvia Sánchez Cámara, Alba Moreno Flores, José Moya Sánchez, Daniel Francisco Pérez Martínez,-Mª Desamparados del Rey Carrión; UCI Hospital Reina Sofía (Murcia): María José Rico Lledó, Juana María Serrano Navarro, Juan Francisco Martín Ruíz, Julián Triviño Hidalgo, África López Ferrer, Isabel Cremades Navalón; UCI Hospital Santa Lucía (Cartagena): Josefa Murcia Payá, JM Allegre Gallego; UCI Hospital Rafael Méndez (Lorca): María del Carmen Lorente; UCI Hospital Universitario Mar Menor (San Javier):Marta Gonsalvez.

Navarra

UCI Hospital Reina Sofía (Tudela): Ruth González Natera, Raquel Garrido López de Murillo, Tania Ojuel Gros,Raquel Flecha Viguera, Isabel López González; UCI Hospital García Orcoyen(Estella-Lizarra): Adriana García Herrera.

País Vasco

UCI Hospital Universitario de Donostia (Donostia): Loreto Vidaur Tello, Maialen Aseguinolaza, Itziar Eguibar.

Sevilla:

UCI Hospital Universitario Virgen de la Macarena(Sevilla): María Luisa Cantón Bulnes, Jose Javier González Contreras, Helena Pérez Chomón, Nerissa Álvarez Chicote, Alberto Sousa González.

Valencia:

UCI Hospital Universitario de La Ribera (Alzira): Asunción Marqués Parra, Sergio García Marti, Alberto Lorenzo Aguilar, Laura Bellver Bosch, Victor Gascón Sanchez, Sonia De la Guía Ortega. UCl Hospital Dr. Peset (Valencia): Martín Parejo Montell, Alberto Belenguer Muncharaz, Hector Hernández Garces, 
Victor Ramírez Montero, Mónica Crespo Gómez, Verónica Martí Algarra; UCI

Hospital Universitari i Politècnic La Fe (Valencia): Susana Sancho Chinesta,

Joaquin Arguedas Cervera, Faustino Álvarez Cebrian, Begoña Balerdi Pérez,

Rosa Jannone Fores, Javier Botella de Maglia; UCI Hospital Clínico Universitario

de Valencia (Valencia): Nieves Carbonell Monleón, Jose Ferreres Franco, Ainhoa

Serrano Lazaro, Mar Juan Díaz, María Luisa Blasco Cortés; UCI Hospital Virgen

de los Lirios de Alcoy (Alicante): Laura Fayos, Julia Giménez, Gaspar Soriano,

Ricardo Navarro. UCI Hospital Arnau de Vilanova (Valencia): Sonia Mas, Elena

Bisbal, Laura Albert, Johncard Romero, Juan Fernández Cabreara; UCI Hospital

Comarcal de Vinarós (Vinarós): Andrea Ortíz.

Principado de Andorra

ICU Hospital Nostra Señyora de Meritxell (Les Esclades): Antonio Margarit

Ribas.

\section{Funding}

This study was supported by the Spanish Intensive Care Society (SEMICYUC), Ricardo Barri Casanovas Foundation Grant (A. Rodríguez) and) and Grant of Pla Estratègic de Recerca i Innovació en Salut- Generalitat de Catalunya PERIS SLT017/20/000030 (M.Bodi, M Ruíz-Botella, J Gómez, A.Rodríguez). The study sponsors have no role in the study design, data collection, data analysis, data interpretation, or writing of the report.

\section{Conflicts of interest/Competing interests (include appropriate disclosures)}

All authors declare that they have no conflicts of interest

\section{Availability of data and material (data transparency)}

The anonymized database collected for the study by the SEMICYUC, and the data dictionary that defines each field in the set, will be made available to reviewers if they consider it necessary prior confidentiality agreement.

\section{Code availability (software application or custom code)}

The software used for the analysis was R (cran.r-project.org). All code can be obtained on GitHub

\section{Authors' contributions}

Alejandro Rodríguez, Gerard Moreno, Manuel Ruiz-Botella, Ignacio Martín-Loeches, María Jiménez Herrera, Jordi Sole-Violán, Josep Gómez, María Bodí, Sandra Trefler, Fernándo Armestar, Asunción Marques Parra, Angel Estella, Ruth Jorge García, Pablo Vidal-Cortes, Emili Díaz, Ricard Ferrer, Antonio AlbayaMoreno, Ana Loza, Laura Sánchez Montori, María deAlba-Aparicio, Mercedes Nieto, Judith Marín-Corral, Lorena Forcelledo Espina and Immaculada Vallverdú had substantial contributions to conception and design of the work.

Alejandro Rodríguez, Sandra Trefler, Manuel Ruiz-Botella, Ana Casamitjana Ortega, Fátima Martín Serano, Josep Gómez, Josep María Bonell Goytisolo, Susana Sancho Chinesta, Virgina Fraile Gutierrez, Angel Estella and Lorenzo Socias Crespi had substantial contribution for data acquisition

Alejandro Rodríguez, Gerard Moreno, Manuel Ruiz-Botella, Ignacion Martín-Loeches, Josep Gomez, María Bodí, Judith Marín-Corral, Antonio Alabaya Moreno and Angel Estella had substantial contribution for data analysis and interpretation of data for the work

Alejandro Rodríguez, Gerard Moreno, Ignacio Martín-Loeches, Josep Gómez and Emili Díaz drafting of the manuscript

Ricard Ferrer, María Bodí, Judith Marín-Corral, Juan Carlos Pozo Laderas, Antonio Albaya Moreno and Jordi Solé-Violán critically reviewed the draft manuscript

The corresponding author (Alejandro Rodríguez) had full access to all the data in the study and takes responsibility for the integrity of the data and the accuracy of the data analysis. All authors approved the final version of the manuscript. The views expressed in this article are those of the authors and not necessarily those of the SEMICYUC.

\section{Ethical Approval and Consent to participate}

The study was approved by the reference institutional review board at Joan XXIII University Hospital (IRB\# CEIM/066/2020) and each participating site with a waiver of informed consent 
Acknowledgements: Alexis Garduno, MSc provided a factual review and helped edit the manuscript and the COVID-19/SEMICYUC Working Group (complete list of investigator in Appendix 2)

\section{References}

1. Thompson BT, Chambers RCLK. Acute respiratory distress syndrome. N Engl J Med. 2017;10(377):562-72. doi:10.1056/NEJMra1608077.

2. Ware LMM. The Acute Respiratory Distress Syndrome. N Engl J Med. 2000;342(18):1334-49.

3. Phua J, Stewart TE, Ferguson ND. Acute respiratory distress syndrome 40 years later: Time to revisit its definition. Crit Care Med. 2008;36(10):2912-21. doi:10.1097/CCM.0b013e31817d20bd.

4. Arabi YM, Chrousos GP, Meduri GU. The ten reasons why corticosteroid therapy reduces mortality in severe COVID-19. Intensive Care Med. 2020;46(11):2067-70. doi:10.1007/s00134-020-06223-y.

5. De Pascale G, Bello G, Dell'Anna AM, et al. Steroids and severe pneumonia. Ready for the winter? Discussion on "Corticosteroid treatment in critically ill patients with severe influenza pneumonia: a propensity score matching study. Intensive Care Med. 2018;44(12):2319-20. doi:10.1007/s00134-018-54143.

6. Peter JV, John P, Graham PL, Moran JL, George IA, Bersten A. Corticosteroids in the prevention and treatment of acute respiratory distress syndrome (ARDS) in adults: Meta-analysis. Bmj. 2008;336(7651):1006-9. doi:10.1136/bmj.39537.939039.BE.

7. Ewald H, Raatz H, Boscacci R, Furrer H, Hc B, Briel M. Adjunctive corticosteroids for Pneumocystis jiroveci pneumonia in patients with HIV infection (Review) SUMMARY OF FINDINGS FOR THE MAIN COMPARISON. Cochrane Database Syst Rev. 2015;(4):1-28. doi:10.1002/14651858.CD006150.pub2.www.cochranelibrary.com.

8. Hui DS. Systemic corticosteroid therapy may delay viral clearance in patients with middle east respiratory syndrome coronavirus infection. Am J Respir Crit Care Med. 2018;197(6):700-1. doi:10.1164/rccm.201712-2371ED.

9. Arabi YM, Mandourah Y, Al-Hameed F, et al. Corticosteroid therapy for critically ill patients with middle east respiratory syndrome. Am J Respir Crit Care Med. 2018;197(6):757-67. doi:10.1164/rccm.201706-11720C.

10. Rodrigo C, Leonardi-Bee J, Nguyen-Van-Tam J, Lim WS. Corticosteroids as adjunctive therapy in the treatment of influenza (Review). Cochrane Database Syst Rev. 2016;(3):1-51. doi:10.1097/CCM.0000000000004093.

11. Moreno G, Rodríguez A, Reyes LF, et al. Corticosteroid treatment in critically ill patients with severe influenza pneumonia: a propensity score matching study. Intensive Care Med. 2018;44(9):1470-82. doi:10.1007/s00134-018-5332-4.

12. RECOVERY collaborative Group. Dexamethasone in Hospitalized Patients with Covid-19 - Preliminary Report. N Engl J Med. $2020: 1-11$. doi:10.1056/nejmoa2021436.

13. Li Y, Meng Q, Rao X, et al. Corticosteroid therapy in critically ill patients with COVID-19: a multicenter, retrospective study. Crit Care. 2020;24(1):1-10. doi:10.1186/s13054-020-03429-w.

14. Liu J, Zhang S, Dong X, et al. Corticosteroid treatment in severe COVID-19 patients with acute respiratory distress syndrome. J Clin Invest. 2020;130(12):6417-28. doi:10.1172/jci140617.

15. WHO. Corticosteroids for COVID-19. Living Guid - 2 Sept 2020. 2020:1-25. https://www.who.int/publications/i/item/WHO-2019-nCoV-Corticosteroids2020.1\%0Ahttps://app.iloveevidence.com/loves/5e6fdb9669c00e4ac072701d? question_domain=5b1dcd8ae611de7ae84e8f14\&population=5e7fce7e3d05156b5f5e032a\&intervention=5d2b2b62daeedf1d3af33331.

16. NIH. Coronavirus Disease 2019 (COVID-19) Treatment Guidelines. Disponible en: https://covid19treatmentguidelines.nih.gov/. Nih. 2020;2019:130.

17. Weile J, Streeck B, Muck J, et al (2009) Severe cytomegalovirus-associated esophagitis in an immunocompetent patient after short-term steroid. therapy. J Clin Microbiol 2009; 47:3031-3033. https:// doi. org/ 10. 1128/ JCM.00143- 09.

18. Kumar A, Paulose R, Sadasivan S, et al (2020) Sarcoidosis, steroids and Strongyloides\&\#8212.

19. what's the catch? Clin Microbiol Infect. 2020. https:// doi. org/ 10. 1016/j.cmi. 2020. 09. 012.

20. Chaudhuri D, Sasaki K, Karkar A, et al. Corticosteroids in COVID-19 and non-COVID-19 ARDS: a systematic review and meta-analysis. Intensive Care Med. 2021. https://doi.org/10.1007/s00134-021-06394-2.

21. - Ye Z, Wang Y, Colunga-Lozano LE, et al. Efficacy and safety of corticosteroids in COVID-19 based on evidence for COVID-19, other coronavirusinfections, influenza, community-acquired pneumonia and acute respiratory distress syndrome: a systematic review and meta-analysis. CMAJ. 2020;192:E756-67. doi:10.1503/cmaj.200645.

22. Chen $\mathrm{H}, \mathrm{Xie} \mathrm{J}$, Su N, et al. Corticosteroid therapy is associated with improved outcome in critically ill COVID-19 patients with hyperinflammatory phenotype. Chest. 2020. doi:10.1016/j.chest.2020.11.050.

23. Rodríguez A, Ruiz-Botella M, Martín-Loeches I, et al. Deploying unsupervised clustering analysis to derive clinical phenotypes and risk factors associated with mortality risk in 2022 critically ill patients with COVID-19 in Spain. Crit Care. 2021;25:63. doi:10.1186/s13054-021-03487-8.

24. Bellomo R. Ronco C. Kellum JA, et al. Acute renal failure-definition, outcome measures, animal models, fluid therapy and information technology needs: the Second International Consensus Conference of the Acute Dialysis Quality Initiative (ADQI) Group. Crit Care. 2004 ; 8: R204-R212.

25. Sato-llic M. Homogeneous cluster analysis. Procedia Comput Sci. 2018;140:269-75. doi:10.1016/j.procs.2018.10.320.

26. Sommet N, Morselli D ., Mplus R. Keep Calm and Learn Multilevel Logistic Modeling: A Simplified Three-Step Procedure Using Stata. and SPSS. International Review of Social Psychology. 2017;30(1):203-18. DOl:https://doi.org/10.5334/irsp.90.

27. Austin PC, Stuart AE. Optimal full matching for survival outcomes: a method that merits more widespread use. Stat Med. 2015;34:3949-67. 
28. Schoenfeld D. Partial Residuals for The Proportional Hazards Regression Model. Biometrika, 1982;69 (1): 239-41.http://links.jstor.org/sici? sici=00063444\%28198204\%2969\%3A1\%3C239\%3APRFTPH\%3E2.0.CO\%3B2-3.

29. Fine JP, Gray RJ. A Proportional Hazards Model for the Subdistribution of a Competing Risk. J Am Stat Assoc. 1999;94(446):496-509. doi:10.1080/01621459.1999.10474144.

30. Dekker FW, de Mutsert R, van Dijk PC, et al. Survival analysis: time-dependent effects and.

31. time-varying risk factors. Kidney Int. 2008;74:994-7. doi:10.1038/ki.2008.328.

32. Dunkler D, Ploner M, Schemper M, Heinze G. Weighted Cox Regression Using the R Package coxphw. J Stat Softw. 2018;84(2):1-26. doi:10.18637/jss.v084.i02.

33. Auyeung TW, Lee JSW, Lai WK, et al. The use of corticosteroid as treatment in SARS was associated with adverse outcomes: A retrospective cohort study. J Infect. 2005;51(2):98-102. doi:10.1016/j.jinf.2004.09.008.

34. Lee KH, Yoon S, Jeong GH, et al. Efficacy of Corticosteroids in Patients with SARS, MERS and COVID-19: A Systematic Review and Meta-Analysis. J Clin Med. 2020;9(8):2392. doi:10.3390/jcm9082392.

35. Cano EJ, Fonseca Fuentes X, Corsini Campioli C, et al. Impact of Corticosteroids in Coronavirus Disease 2019 Outcomes: Systematic Review and Metaanalysis. Chest. 2020. doi:10.1016/j.chest.2020.10.054.

36. De Backer D, Azoulay E, Vincent JL. Corticosteroids in severe COVID-19: a critical view of the evidence. Crit Care. 2020;24(1):1-3. doi:10.1186/s13054020-03360-0.

37. Li H, Chen C, Hu F, et al. Impact of corticosteroid therapy on outcomes of persons with SARS-CoV-2, SARS-CoV, or MERS-CoV infection: a systematic review and meta-analysis. Leukemia. 2020;34(6):1503-11. doi:10.1038/s41375-020-0848-3.

38. Pasin L, Navalesi P, Zangrillo A, Kuzovlev A, Fresilli S. Corticosteroids for Patients With Coronavirus Disease 2019 (COVID-19) With Different Disease Severity: A Meta-Analysis of Randomized Clinical Trials. J Cardiothorac Vasc Anesth. 2021;35:578-84.

39. Contou D, Fraissé M, Pajot O, Tirolien JA, Mentec H, Plantefève G. Comparison between first and second wave among critically ill COVID-19 patients admitted to a French ICU: no prognostic improvement during the second wave? Crit Care. 2021;25:3. doi:10.1186/s13054-020-03449-6.

40. Wu C, Hou D, Du C, et al. Corticosteroid therapy for coronavirus disease 2019-related acute respiratory distress syndrome: a cohort study with propensity score analysis. Crit Care. 2020;24(1):1-10. doi:10.1186/s13054-020-03340-4.

41. Xiang L, Marshall,GD Jr. Immunomodulatory effects of dexamethasone on gene expression of cytokine and stress hormone receptors in peripheral blood mononuclear cells. Int Immunopharmacol. 2013;17:556-60.

42. Coutinho AE. Chapman KE.The anti-inflammatory and immunosuppressive effects of glucocorticoids, recent developments and mechanistic insights. Mol Cell Endocrinol. 2011;335(1):2-13.

43. Mazer MB, Davitt E, Turnbull IR, et al. In Vitro-Administered Dexamethasone Suppresses T Cell Function With Reversal by Interleukin-7 in Coronavirus Disease 2019.

44. Gershengorn HB. Early adoption of critical care interventions is unjustifiable without concomitant effectiveness study. Crit Care. 2020;24(1):10-2. doi:10.1186/s13054-020-03382-8.

45. Mattos-silva P, Felix NS, Silva PL, et al. Pros and cons of corticosteroid therapy for COVID-19 patients. Respir Physiol Neurobiol. 2020;280:103492. doi:doi.org/10.1016/j.resp.2020.103492.

46. Gupta S, Hayek SS, Wang W, et al. Factors Associated with Death in Critically III Patients with Coronavirus Disease 2019 in the US. JAMA Intern Med. 2020;02115:1-11. doi:10.1001/jamainternmed.2020.3596.

47. Huang C, Wang Y, Li X, et al. Clinical features of patients infected with 2019 novel coronavirus in Wuhan, China. Lancet. 2020;395(10223):497-506. doi:10.1016/S0140-6736(20)30183-5.

48. Price-Haywood EG, Burton J, Fort D, Seoane L. Hospitalization and Mortality among Black Patients and White Patients with Covid-19. N Engl J Med. 2020;382(26):2534-43. doi:10.1056/nejmsa2011686.

49. Schmidt M, Hajage D, Demoule A, et al. Clinical characteristics and day-90 outcomes of 4244 critically ill adults with COVID-19: a prospective cohort study. Intensive Care Med. 2020;33(0):1-54. doi:10.1007/s00134-020-06294-x.

\section{Figures}


Figure $1 \mathrm{~A}$

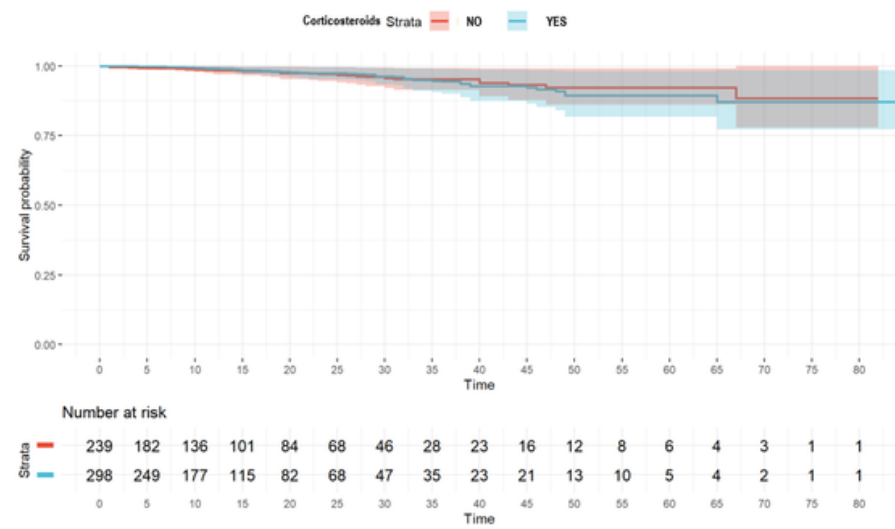

Figure 1B

Cumulative incidence functions

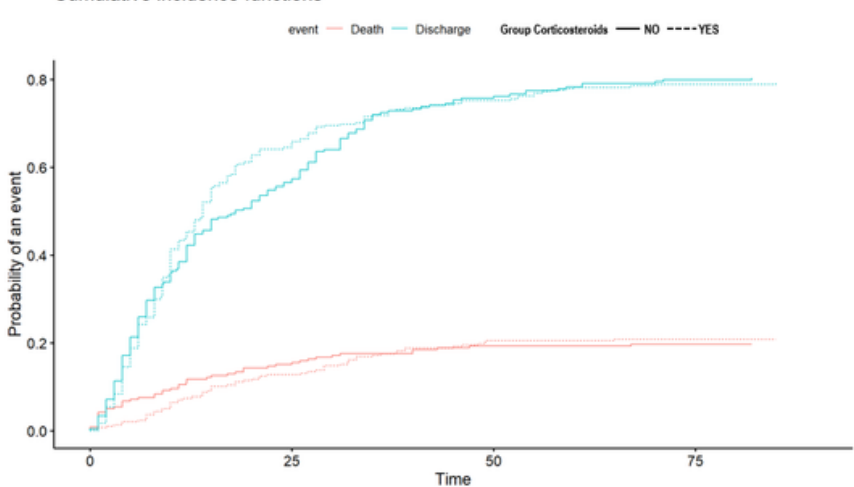

Figure 1

Cox proportional hazard regression plot (A) and competing risk plot by Fine and Gray analysis (B) among patient's A phenotype

Figure $2 \mathrm{~A}$

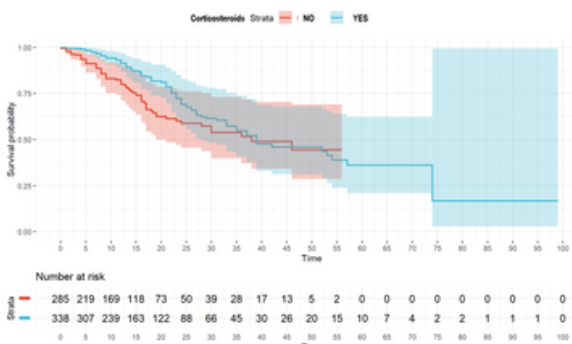

Figure 28

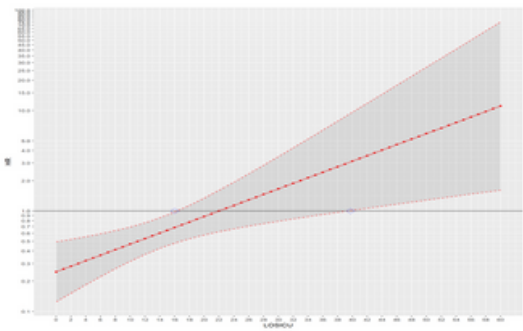

Figure $2 \mathrm{C}$

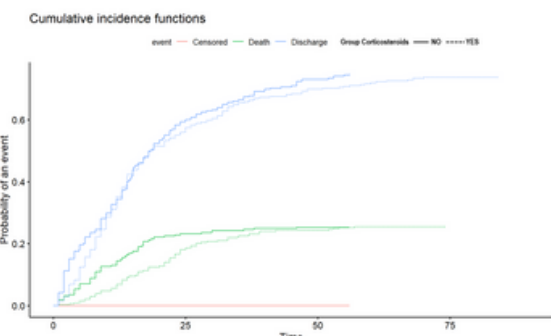

Figure 2

Cox proportional hazard regression plot (A), Cox time step interaction plot (B) and competing risk plot by Fine and Gray analysis (C) among patient's B phenotype

Figure $3 \mathrm{~A}$

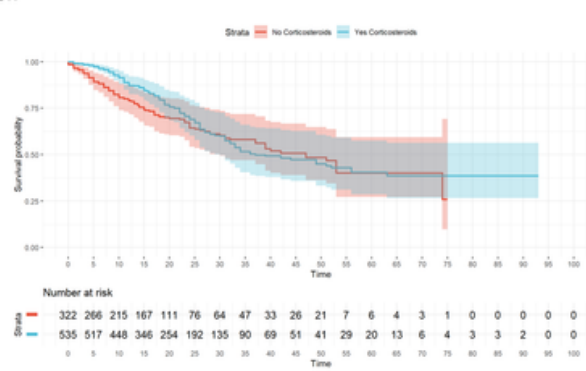

Figure 3

Cox proportional hazard regression plot (A), Cox time step interaction plot (B) and competing risk plot by Fine and Gray analysis (C) among patient's $C$ phenotype

\section{Supplementary Files}

This is a list of supplementary files associated with this preprint. Click to download.

- Appendix1.docx

- ListadosgrupoCOVID1919.02.docx

- STROBEchecklistcohort.docx
Figure 3 B

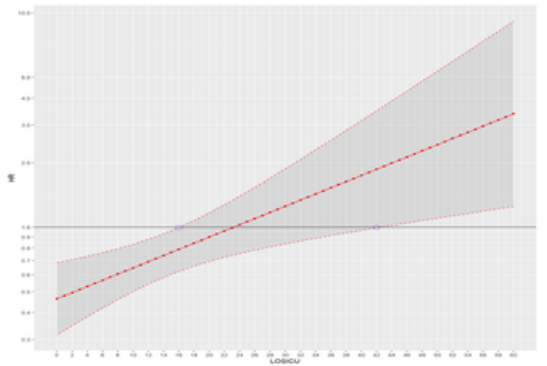

Figure $3 \mathrm{C}$

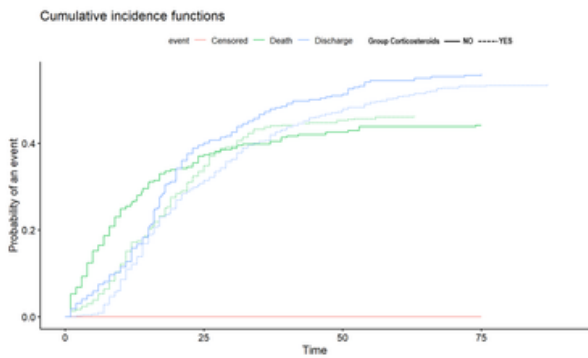

